Research Article

\section{The different levels of depression and anxiety among Pakistani professionals}

\author{
Sehrish Hassan ${ }^{1 *}$ and Waqar Husain ${ }^{2}$ \\ 'Lecturer of Psychology, Department of Humanities, COMSATS University Islamabad, Islamabad, \\ Pakistan \\ ${ }^{2}$ Assistant Professor of Psychology, Department of Humanities, COMSATS University Islamabad, \\ Islamabad, Pakistan
}

\section{Abstract}

The present study was conducted to examine the relationship between work-stress, depression and anxiety among six major professionals (doctors, engineers, bankers, nurses, teachers, and lawyers). The inquiry included 260 professionals from different private and governmental sector organizations of Rawalpindi and Islamabad, Pakistan. Job Stress Scale and the subscales of Depression, Anxiety \& Stress Scale for depression and anxiety were administered. Based on the hypotheses, a strong positive correlation was found between work stress and depression \& anxiety. The current study revealed that stress at work not only prevailed among different Pakistani professionals on severely alarming levels but significantly contributed in developing depression and anxiety.

\section{More Information}

*Address for Correspondence: Sehrish Hassan, Lecturer of Psychology, Department of Humanities, COMSATS University Islamabad, Islamabad, Pakistan, Email: sehrishhassan@ymail.com

Submitted: 10 February 2020

Approved: 04 March 2020

Published: 05 March 2020

How to cite this article: Hassan S, Husain W. The different levels of depression and anxiety among Pakistani professionals. Insights Depress Anxiety. 2020; 4: 012-018.

DOI: 10.29328/journal.ida.1001014

Copyright: (c) 2020 Hassan S, et al. This is an open access article distributed under the Creative Commons Attribution License, which permits unrestricted use, distribution, and reproduction in any medium, provided the original work is properly cited.

Keywords: Work stress; Depression; Anxiety

Check for updates

(9) OPEn ACCESS

\section{Introduction}

The phenomenon of work related stress has been studied extensively since last few decades as evidence by number of books, literature and reviews [1,2]. Different researches anticipated that occupational/work related stress causes companies more than $\$ 17$ billion annually [3]. Present study examines the relationship between work stress, depression and anxiety among six major professionals of Pakistan.

\section{Depression}

Depression has become most critical health concern worldwide and leading cause of practical disability and mortality. According to a rough estimate by [4]. Major depressive disorder is the leading cause of disability in the U.S. for ages 15-44. Untreated depression in number one risk for suicides and mortality. Diagnostic and Statistical Manual of Mental Disorders [5,6] defines depression as "Distinct episodes of at least 2 weeks' duration involving clear-cut changes in mood, cognition and neurodegenerative functions and inter-episode remission".

(DSM-V 2013) Criteria for depressive disorder is as follows;

A. "Five (or more) of the following symptoms have been present during the same 2 week period and represent a change from previous functioning; at least one of the symptom is either (1) depressed mood or (2) loss of interest or pleasure.

1. Depressed mood most of the day, nearly every day, as indicated by either subjective report (e.g., feels sad, empty, and hopeless) or observation made by others (e.g. appears tearful). (Note; In children and adolescents, can be irritable mood).

2. Markedly diminished interest or pleasure in all, or almost all activities most of the day, nearly every day (as indicated by either subjective account or observation).

3. Significant weight loss when not dieting or weight gain (e.g. a change of more than $5 \%$ of body weight in a month) or decrease or increase in appetite nearly every day. (Note; in children, consider failure to make expected weight gain).

4. Insomnia or hypersomnia nearly every day.

5. Psychomotor agitation or retardation nearly every day (observable by others not merely subjective report of restlessness or being slowed down).

6. Fatigue or loss of energy nearly every day.

7. Feeling of hopelessness or excessive or inappropriate 
guilt (which may be delusional) nearly every day, (not merely self-reproach or guilt about being sick).

8. Diminished ability to think or concentrate, or indecisiveness, nearly every day (either by subjective account or observed by others).

9. Recurrent thoughts of death (not just fear of dying), recurrent suicidal ideation without a specific plan, or a suicide attempt or a specific plan for committing suicide.

\section{A. The symptoms cause clinically significant distress or impairment in social occupational, or other important areas of functioning.}

B. The episode is not attributable to the physiological effect of a substance or to another medical condition. Note: Criterion A-C represent a major depressive episode.

C. The occurrence of major depressive episode is not better explained by schizoaffective disorder, schizophrenia, schizopherniform disorder, delusional disorder or other specified and unspecified schizophrenia spectrum and other psychotic disorders.

D. There has never been a manic episode or a hypomanic episode.

\section{Anxiety}

Anxiety disorders include disorders that share features of excessive fears and anxiety and related behavioral disturbances. Fear is the emotional response to real or perceived imminent threat, whereas "anxiety is anticipation of future threat" (DSM-V 2013). Work related stress can contribute in the development of anxiety, when employees encounter job insecurity, work load, imbalance of effort and reward, poor relations with employer they are more probable to develop anxiety disorders.

Symptoms of anxiety disorder includes excessive worries, restlessness, agitation and fatigue, poor concentration, muscular tension, poor sleep patterns, irritability, palpitation, hot flashes or chills, irrational fear, trembling heart and panic attack.

Work and family are the two significant domains where people spent most of their time and get pleasure and satisfaction from them equally they are considered as the common cause of tensions and worries. Globalization of the world economy and economic rationalization have changed working environment and caused major job changes, greater part-time, temporary jobs rather than permanent, and greater workload demands that are leading to greater uncertainty and pressure. Due to these changes working conditions are increasingly considered as the source of much of stress and strain [7]. Parker and De Cottiis [1], defined work stress as" Work stress involves two main factors time pressure and anxiety, time pressure is the disparity between the demands of the jobs and time available to accomplish them, whereas anxiety is a negative emotional and reactive stage that employees experience as a result of strain due to their job requirements".

Avshalom Caspi, et al. [8], found the effect of work stress on diagnosed depression and anxiety in young working adults. Work stress which involve different other job related factors (work demands, power of making important decisions, low work social support, physical work demands) was measured by interview. Major depressive disorder (MDD) and generalized anxiety disorder (GAD) were assessed by Diagnostic Interview Schedule (DIS) and diagnosed according to DSM-IV criteria. They found that the participants who encountered high job demands are more vulnerable to MDD or GAD compared to those with low job demands.

Larisch, M, et al. [9], found the association between psychosocial stress at work and depressive symptoms among middle age employees. 23 item Likert- scale questionnaire was used (based on effort-reward imbalance) to measure psychosocial stress at work and depressive symptoms were assessed by the German version of the CES-D scale. The sample consisted of 316 ( $44.6+/-7.5$ years) men and women employees. By controlling all the confounding variables, findings indicated high efforts and low reward jobs are associated with depressive symptoms.

Isablle Godin, et al. [10-12], conducted much similar research to find the relationship between work-stress and five indicators of mental health (depression, anxiety, somatization, chronic fatigue and psychotropic drug consumption at work respectively). They studied white collar workers from four different enterprises to include contextual variation in study. Collected data in two steps (T1 2000) and (T2 2001) exact after one year interval by using standardized measure of both work stress and mental health, Therefore work stress was defined in four categories (a) workers free from stress at both measure (b) Stress only in the first measure not in second (c) recent onset of job stress as evidence by second measure (d) stress at both measures. Results from multivariate analysis indicated positive correlation between work stress depression, anxiety and somatization, whereas less clear patterns for chronic fatigue and consumption of drugs. Participants who confronted continuous and incident job stress showed higher proportion of mental health problems compared to those who had minimum job stress.

According to a rough estimate depression and anxiety will be the most critical heath concerns in coming few years. Therefore, there exist a strong need to explore the risk factors contributing in increased psychopathology. People spend most of their time with families and at work place, Therefore these two domains are considered two main sources of pleasure as well as many conflicts. 
In the light of prior researches on work stress, it can be said that work stress has become a major dilemma for employers, employees and many organizations as well, because it negatively effects productivity, employee's health and organizational image by increasing burnout, absenteeism and turn over.

Researchers found in literature were typically focused on organizational aspects of work stress i.e. job control. Decision latitude, reward system, time pressure, social support, work load and their relationship with employee's satisfaction and organizational commitment. The need is to look for the factors that are in subjective control. Most of previous work on occupational stress covers only single profession i.e. health care professional (doctors, nurses, and Paramedical staff), teachers, law enforcement professions (lawyers and police officers) and managerial level profession. Present study is first ever attempt in Pakistan to incorporate major professions including doctors, nurses, engineers, bankers, teachers and lawyers simultaneously. The study will provide a broad picture about the level of work stress in our professionals, and it will further tell about prevalence and probability of depression and anxiety among these professionals, it will further examine the role of different demographic factors i.e. gender, educational qualification, marital status, job sector, working hours, monthly income in the development of work stress.

It will help to understand which major contributors in developing work stress, whether it is their gender (being male or female), marital status (being married or single), job sector (private vs. government), working long hours and monthly income (highly paid and with average monthly salary) that make employees vulnerable to work stress. Comparison between six professionals will highlight the profession which are at higher risk of having work stress, depression and anxiety.

The purpose of the present study is not to make people scared about their psychological condition or not to label them psychopath but it will be a step towards awareness about the elevated level of work stress and subsequent psychopathology. Because in our culture people take such issues for granted due to many reasons that can be more hazardous for them e.g. complete burnout from work, multiple psychosomatic complaints and in extreme cases depression, anxiety as well as suicide. Present study will sensitize people about potential risk. When people will become conscious they will start avoid conflicts and will seek help.

Different interventions, training and management plans can be develop on individual as well as organizational level upon the findings of the present study.

\section{Objectives of the study}

Including six major professionals working in private and public sector of Rawalpindi/Islamabad, the study is designed to
1. To find the relation between workstress and depression

2. To find the relation between work stress and anxiety.

\section{Method}

The current study applied a "Correlational research design". There were 3 dependent variables of the study i.e. Work stress, anxiety \& depression. The study included 7 independent variables i.e. sex, marital status, educational qualification, job sector, profession, monthly income and number of working hours.

\section{Procedure}

The present study was conducted on July 2016 upon six major professionals (i.e. doctors, bankers, engineers, teachers, lawyers and nurses) of Rawalpindi and Islamabad to study their level of work stress and subsequent psychological problems in them, Participants were taken from different private and public sector organizations. Standardized questionnaire were used to gather data. Before data collection and encounter with research participants researchers first obtained written consent form from the administration of every organization, authorizes were informed about the rationale and purpose of the study and type of information needed from their employees. Participants were approached personally by the researcher. Random and purposive sampling technique was used.

At the end of demographic questionnaire a written consent form was available for seeking signature from the participants on their willingness. This information did not include their identities. All the participants of the current study were educated and were familiar with English. The average education level of the participants was graduation. The terminologies related to depression, anxiety used in the instruments were thought to be easily understood by the participants in English .It would have created more problems in understanding the terminologies if the translated version of the instruments were provided to the participants. The subjects and the facilitators were thanked a lot for their cooperation.

\section{Participants}

The research participants were 260 professionals (males 143 and female 116) (i.e. doctors, teachers, nurses, bankers, lawyers and engineers) of Rawalpindi/Islamabad, who further included male professionals $(n=143)$ and female professionals $(n=116)$, married professionals $(n=130)$ and unmarried professionals $(n=129) ;(n=93)$ professionals working in government job sector and $(n=166)$ working in private job sector. Among $\mathrm{N}=280$ division according to different professions is; doctors $(n=60)$, bankers $(n=49)$, lawyers $(n=28)$, engineers $(n=46)$, teachers $(n=43)$ and nurses $(n=33)$. These professionals were taken from the major institutes both private and government (i.e. hospitals, universities, banks, law courts) of twin cities (Rawalpindi/ 
Islamabad) average age range of the participants ranges between 35 to 50 years. All the participants as belong to welleducated class having good socio-economic background and all were in good physical health.

\section{Instruments}

Following instruments were used to measure level of work stress, depression and anxiety among professionals.

Work stress scale: Work stress was measured by Parker and De Cotiis [1], Scale of work stress which focuses on organizational and work related stress. The scale measures feelings of discomfort, stress and work anxiety and also measure motivation, organizational commitment and satisfaction. The test consists of 13 items which are rated on a point-five likert scale ranging from (strongly disagree) 0 to (strongly agree) 4 . It is a two dimensional scale which focus on time pressure and anxiety. Both dimensions i.e. time pressure and anxiety are measured by 6 items each. High score indicated high level of time pressure and anxiety which shows high level of work related stress. The overall reliability of the scale is appropriate .88 and the reliabilities of time pressure and anxiety items are .78 and .75 respectively.

Depression anxiety and stress scale [13]: Two subscales (depression and anxiety) of Depression, Anxiety and Stress Scale (DASS) were administered. The DASS contains 42 items, three subscales namely (depression, anxiety and stress) 14 items for each of the subscale. The test evaluates negative emotional state since past seven days, it is 4 point likert scale ranging from 0 to 4 test takers are asked to rate their emotional and reactive state from least to maximum number since last week. The test is developed and standardized on non-clinical sample, therefore it is more appropriate to use with normal adolescents and adults, and this property makes DASS more preferred tool to assess depression and anxiety for research purpose.

DASS is a standardized scale that has been used for clinical and research purpose since many years. The subscales have high internal consistency and appropriate reliability, Cronbach's Alpha reliability of (Depression*Anxiety) is (.93) and reliabilities for separate subscales Depression (.92) and Anxiety (.88). The Depression scale measures loss of interest, sadness, inactivity and lethargy and hopelessness high score on this scale indicates despair and gloomy mood, loss of pleasure difficulty in taking initiatives and pessimism about future. The Anxiety scale measures nervousness, excessive worries, fears, autonomic arousal, and subjective experience of anxious affect high score on this scale indicates apprehension, physiological symptoms of anxiety. Norms and cut off scores are available to facilitate analysis.

\section{Results}

The present study intended to examine the relationship between work stress, depression and anxiety among professionals. For this purpose data was collected from 260 professionals namely doctors, bankers, engineers, teachers, lawyers and nurses from different private and governmental organizations of Rawalpindi/Islamabad. Standardized questionnaires were used Job Stress Scale [1], the other is depression and anxiety subscales of Depression Anxiety and Stress Scale [14] to measure level of work stress, depression and anxiety respectively. Psychometric properties of the scales were established by computing item-total correlation, and Cronbach's Alpha. Analysis of the statistical data on SPSS confirms that Job Stress and Depression, Anxiety and Stress scales are reliable.

\section{Psychometric properties of scales}

In order to estimate the internal consistency of Job Stress Scale and two subscale (Depression \& Anxiety) of Depression, Anxiety and Stress Scale (DASS), following analyses were made;

The Job Stress Scale and two subscale (Depression \& Anxiety) of Depression, Anxiety and Stress Scale (DASS), is found reliable by measuring its reliability on Cronbach's alpha whereas the Cronbach's alpha reliability for the Work Stress Scale is excellent (.88), (Depression*Anxiety) is (.93) and reliabilities for separate subscales Depression (.92) and Anxiety (.88). Above table shows the means of work stress, depression and anxiety among six professionals. Nurses with the highest means i.e. (M 34.09, $17.57 \& 20.00$ subsequently of Work stress, Anxiety and Depression) exhibit severe level of all three variables, bankers and doctors are next to them.

\section{Discussion}

The current study was attempted to see the relationship between work stress, depression and anxiety among the professionals including i.e. doctors, nurses, teachers, lawyers, bankers and engineers of different private and government organizations of Rawalpindi/Islamabad.

The Depression, Anxiety and Stress Scale (DASS) is found reliable by measuring its reliability on Cronbach's alpha (Table 1) whereas the Cronbach's alpha reliability for the overall scale (.910); and for its subscales i.e. depression (.782), anxiety (.741), were also calculated. Moreover, in order to see the correlations among the subscales of DASS, values against Pearson Correlation were also calculated.

Work Stress Scale was also a standardized test for measuring work stress in two dimension i.e. time pressure and anxiety. The reliability of the test was measured on Cronbach's

Table 1: Cronbach's Alpha reliability of Work Stress Scale, Depression Anxiety \& Stress Scale (DASS) and its subscales. $N=(260)$.

\begin{tabular}{|c|c|c|c|c|}
\hline Scale & No. of Items & M & S.D & Alpha \\
\hline Work stress scale & 13 & 28.64 & 9.59 & .88 \\
\hline DASS (Depression *Anxiety) & 28 & 29.78 & 18.43 & .93 \\
\hline Depression & 14 & 16.05 & 10.41 & .92 \\
\hline Anxiety & 14 & 13.73 & 10.10 & .88 \\
\hline
\end{tabular}


alpha .88 (Table 1) which is highly reliable. Pearson product moment correlation were also calculated for the items of scale.

The findings revealed that professionals have overall moderate level of depression and anxiety (Table 2; $M=15.00$ i.e.interpreted on DASS as Moderate Depression) anxiety (table 2; $\mathrm{M}=13.55$ i.e. interpreted on DASS as Moderate Anxiety) on Depression, Anxiety and Stress Scale (DASS) and moderate level of work stress 28.90 (Table 3). The previous studied conducted in this regard also reveal that Depression, anxiety and stress are significant outputs in stressful working settings $[11,15]$. Researchers are inclined to explore the relationship between psychosocial job factors and depression, anxiety and stress [16,17]. Occupational stress involve multiple factors initially with source of pressure, external locus of control, psycho-physiological distress and work dissatisfaction which ultimately leads to more severe problems, i.e. depression, anxiety, hopelessness, other mental health harms and in extreme cases suicidal ideation. Iliceto P, et al. [18], found the relationship between occupational stress and some psychopathological problems among health care professionals including 156 nurses and physicians (65 females/94 males). Occupational stress inventory (OSI), temperament scale and Beck hopelessness scale were administered. Results indicated that of casual variables such as work dissatisfaction, absence of type A behavior, and especially external locus of control, psychological and physiological distress were highly correlated with latent variable psychopathology.

Means and standard deviation were computed for each profession separately which revealed that nurses have highest level of work stress (Table 2; $\mathrm{M}=34.09, \mathrm{SD}=9.40$ ), anxiety (Table $2 ; \mathrm{M}=17.57, \mathrm{SD}=8.07$ ) interpreted on DASS a severe anxiety and depression (Table $2 ; \mathrm{M}=20.00, \mathrm{SD}=7.10$ )

Table 2: Means and Standard Deviation of Work Stress, Depression and Anxiety among different professionals $(\mathrm{N}=260)$.

\begin{tabular}{|c|c|c|c|c|}
\hline Profession & $\boldsymbol{n}$ & Work Stress & Anxiety & \begin{tabular}{c} 
Depression \\
\hline Doctors
\end{tabular} \\
\hline Bankers & 40 & $\begin{array}{c}\text { Moderate } \\
(\mathrm{M}=28.56)\end{array}$ & $\begin{array}{c}\text { Moderate } \\
(\mathrm{M}=14.80)\end{array}$ & $\begin{array}{c}\text { Moderate } \\
(\mathrm{M}=17.10)\end{array}$ \\
\hline Lawyers & 28 & Severe & Severe & Severe \\
\hline & & $(30.22)$ & $(17.02)$ & $(18.65)$ \\
\hline Engineers & 46 & $(28.60)$ & Moderate & Mild \\
\hline & & $(12.75)$ & $(13.25)$ \\
\hline Teachers & 43 & Mild & Moderate & Mild \\
\hline & & $(24.74)$ & $(11.15)$ & $(13.95)$ \\
\hline Nurses & 33 & Severe & Mild & Mild \\
\hline & & $(34.09)$ & $(17.57)$ & $(12.81)$ \\
\hline
\end{tabular}

interpreted on DASS severe depression. , doctors (Table 2; M $=28.56, \mathrm{SD}=10.12$ ), anxiety (Table $2 ; \mathrm{M}=14.80, \mathrm{SD}=12.14$ ) and depression (Table $2 ; \mathrm{M}=17.10, \mathrm{SD}=11.72$ ), and bankers are next to them among six professional i.e. Doctors, bankers, lawyers, nurses, teachers and engineers. Nursing profession seems to more vulnerable to different psychological problems due to work stress. One of the very critical reason is their long term encounter with challenging patients.

Farrington, et al. [19], as cited by (Kwok- Bun, C) [20], identified different stressors encountered by nurses e.g. inadequate staffing, dealing with difficult patients, interpersonal conflicts, work overload, night duties, awareness of great responsibility for patients. Such work stressors effect their mental health leading to elevated level of depression and anxiety [20]. Found the negative correlation between work stress and different dimensions of psychological well-being. Their study also indicated that various categories of work stress are associated with depression and anxiety in nursing. Work stress is a strong predictor of depression and anxiety (Table 4). Caspi, et al., [8], found the influence of work stress on depression and anxiety, their results are consistent with present findings that employees who experiences more stress at work had a twofold risk of major depressive disorder and generalized anxiety disorder as compared to employees with less job demands.

Stansfeld. et al. [21,22], found that certain work characteristics are the major contributors of depression and anxiety. Social support and job-control mediates between work stress, depression and anxiety. Adverse psychosocial work characteristics are significant predictors for the onset of subclinical anxiety and depression in the general working population [23].

Yoshizawa, et al. [24], found level of work stress and rate of depression among psychiatric nurses of Japan. Their results were also in the similar direction that nursing profession is at higher risk of having psychological problems especially depression due to work stress. The findings of this study have important implications for future research and for policy development.

It provide awareness about elevated level of work stress, depression and anxiety in our professionals and make professionals conscious about their psychological health, who are considered as more privileged part of every society. Present research also indicate the profession with highest level of work stress and subsequent psychological problems.

Table 3: Mean, Standard Deviation and F-values of Work Stress, Depression and Anxiety on the basis of Profession ( $\mathrm{N}=260)$

\begin{tabular}{|c|c|c|c|c|c|c|c|c|}
\hline- & $\begin{array}{l}\text { Doctors } \\
(n=66)\end{array}$ & $\begin{array}{l}\text { Bankers } \\
(n=120)\end{array}$ & $\begin{array}{r}\text { Lawyers } \\
(n=47)\end{array}$ & $\begin{array}{l}\text { Engineers } \\
\qquad(n=22)\end{array}$ & $\begin{array}{c}\text { Teachers } \\
(n=10)\end{array}$ & $\begin{array}{l}\text { Nurses } \\
(n=33)\end{array}$ & \multirow[t]{2}{*}{$F$} & \multirow[t]{2}{*}{$p$} \\
\hline Variables & $M(S D)$ & $M(S D)$ & $M(S D)$ & $M(S D)$ & $M(S D)$ & & & \\
\hline Work Stress & $28.56(10.12)$ & $30.22(9.30)$ & $28.50(5.88)$ & $26.82(9.64)$ & $24.74(9.23)$ & $34.09(9.40)$ & 4.45 & .001 \\
\hline Anxiety & $14.80(12.14)$ & $17.02(10.42)$ & $12.75(7.83)$ & $11.15(8.24)$ & $7.90(7.61)$ & $17.57(8.01)$ & 6.32 & .000 \\
\hline Depression & $17.10(11.72)$ & $18.65(11.33)$ & $13.25(10.47)$ & $13.95(10.54)$ & $12.81(8.05)$ & $19.27(6.92)$ & 3.07 & 0.00 .01 \\
\hline
\end{tabular}

Between group $=5$, Within group $=253$, Groups total $=258 .{ }^{\star \star} p<.01 .{ }^{\star} p<.05$ 


\begin{tabular}{|c|c|c|c|c|c|c|c|c|c|c|c|c|}
\hline - & $\begin{array}{l}\text { Doctors } \\
(n=66)\end{array}$ & $\begin{array}{l}\text { Bankers } \\
(n=120)\end{array}$ & $\begin{array}{l}\text { Lawyers } \\
(n=47)\end{array}$ & $\begin{array}{l}\text { Engineers } \\
\qquad(n=22)\end{array}$ & $\begin{array}{c}\text { Teachers } \\
(n=10)\end{array}$ & $\begin{array}{l}\text { Nurses } \\
(n=33)\end{array}$ & $\mathrm{F}$ & $\mathrm{i}-\mathrm{j}$ & & S.E & \multicolumn{2}{|c|}{$\begin{array}{l}95 \% \mathrm{Cl} \\
\mathrm{LL} \mathrm{UL}\end{array}$} \\
\hline Variables & $\mathrm{M}(\mathrm{SD})$ & $\mathrm{M}(\mathrm{SD})$ & $\mathrm{M}(\mathrm{SD})$ & $M(S D)$ & $M(S D)$ & $M(S D)$ & & & & & & \\
\hline Work Stress & $28.56(10.12)$ & $30.22(9.30)$ & $28.50(5.88)$ & 26.82(9.64) & $24.74(9.23)$ & $34.09(9.40)$ & 4.44 & $\begin{array}{l}D<N \\
T<B \\
E<N \\
T<N\end{array}$ & $\begin{array}{c}-5.52 \\
5.48 \\
-7.26 \\
-9.34\end{array}$ & $\begin{array}{l}2.00 \\
1.93 \\
2.11 \\
2.14\end{array}$ & $\begin{array}{c}-11.29 \\
-.08 \\
-13.33 \\
-3.18\end{array}$ & $\begin{array}{c}.24 \\
11.04 \\
-1.19 \\
15.50\end{array}$ \\
\hline Anxiety & $14.80(12.14)$ & $17.02(10.42)$ & $12.75(7.83)$ & $11.15(8.24)$ & 7.90(7.61) & $17.57(8.01)$ & 6.22 & $\begin{array}{l}\mathrm{T}<\mathrm{D} \\
\mathrm{T}<\mathrm{B} \\
\mathrm{E}<\mathrm{B} \\
\mathrm{T}<\mathrm{N}\end{array}$ & $\begin{array}{r}6.89 \\
9.11 \\
5.86 \\
-9.61\end{array}$ & $\begin{array}{l}1.91 \\
2.60 \\
1.97 \\
2.22\end{array}$ & $\begin{array}{c}1.38 \\
3.35 \\
.20 \\
-16.04\end{array}$ & $\begin{array}{l}12.40 \\
14.87 \\
11.32 \\
-3.20\end{array}$ \\
\hline Depression & $17.10(11.72)$ & $18.65(11.33)$ & $13.25(10.47)$ & $13.95(10.54)$ & $12.81(8.05)$ & $19.27(6.92)$ & 3.07 & $\begin{array}{l}T<B \\
T<N\end{array}$ & $\begin{array}{r}5.83 \\
-6.45\end{array}$ & $\begin{array}{l}2.13 \\
2.36\end{array}$ & $\begin{array}{c}-.30 \\
-13.26\end{array}$ & $\begin{array}{c}11.98 \\
.34\end{array}$ \\
\hline
\end{tabular}

Between group $=5$, within group +253 , Groups total +258 . ${ }^{\star \star} p<0.01,{ }^{\star} p<0.0$

Depending on the findings of the present study, trainings, interventions and management plans can be develop on individual and organizational level. It also highlight the need of industrial/occupational psychological in every public and private organization that provide counseling and help employees to improve their coping strategies.

\section{Suggestions}

To overcome the limitations of present study following suggestion are given for future researchers.

1. To bring diversity and to generalize the findings, large number of participant must be taken from diverse group i.e. different culture, localities.

2. Sample size should be equal on all aspects, gender (equal males and females), marital status (equal number of married and single) etc.

3. All the possible factors and biases must be ruled out that are supposed to alter the results or participant's responses.

4. Questions must be asked indirectly (especially about psychological problems) to bring original responses.

5. Two groups must be taken (i.e. professional or unprofessional) that are comparable on all aspects except variables being studied.

\section{References}

1. Parker DF, DeCotiis TA. Organizational Determinants of Job Stress. Organizational Behavior and Human Performance. 1983; 32: 160-177.

2. Lovibond PF, Lovibond SH. The structure of negative emotional states: Comparison of the Depression Anxiety Stress Scales (DASS) with the Beck Depression and Anxiety Inventories. Behav Res Ther. 1995; 33: 335-343.

PubMed: https://www.ncbi.nlm.nih.gov/pubmed/7726811

3. Khaled B, Al-Shammari IS, Jefri OA. Occupational Stress in Different Organizations: A Saudi Arabian Survey. Electronic Version. J Managerial Psychology. 1995; 10: 24-28.

4. Levav I, Rutz W. World Health Organization: The world health report 2001 - Mental Health: New understanding, New Hope. Isr J Psychiatry Relat Sci. 2002; 39: 50-56.

PubMed: https://www.ncbi.nlm.nih.gov/pubmed/12013710
5. American Psychiatric Association. Diagnostic and statistical manual of mental disorders (5th Ed.). Washington, DC. 2013.

6. American Psychiatric Association. Diagnostic and statistical manual of mental disorders (4th ed., text rev.). Washington, DC. 2000.

7. Tennant C. Work-related stress and depressive disorders. J Psychosom Res. 2011; 51: 697-704.

PubMed: https://www.ncbi.nlm.nih.gov/pubmed/11728512

8. Melchio M, Caspi A, Milne BJ, Danese A, Poulton R, et al. Work stress precipitates depression and anxiety in young, working women and men. Psychol Med. 2007; 37: 1119-1129.

PubMed: https://www.ncbi.nlm.nih.gov/pubmed/17407618

9. Larisch M, Joksimovic L, Starke D, Siegrist J. Effort-reward imbalance at work and depressive symptoms-a cross-sectional investigation of middle-aged employees. Psychother Psychosom Med Psychol. 2003; 53: 223-228.

PubMed: https://www.ncbi.nlm.nih.gov/pubmed/12709890

10. Godin I, Kittel F, Coppieters Y, Siegrist J. A Prospective Study of Cumulative Job Stress in Relation to Mental Health. BMC Public Health. 2005; 5: 67.

PubMed: https://www.ncbi.nlm.nih.gov/pubmed/15958170

11. Siegrist J, Starke D, Chandola T, Godin I, Marmot M, et al. The measurement of effort-reward imbalance at work: European comparisons. Soc Sci Med. 2004; 58: 1483-1499.

PubMed: https://www.ncbi.nlm.nih.gov/pubmed/14759692

12. Siegrist J. Adverse Health Effects of High Effort/Low Reward Condition. J Occup Health Psychol. 1996; 1: 27-41.

PubMed: https://www.ncbi.nlm.nih.gov/pubmed/9547031

13. Lovibond SH, Lovibond PF. Manual for the Depression Anxiety Stress Scales. (2nd. Ed.) Sydney: Psychology Foundation. 1995.

14. Lovibond P. Long-term stability of depression, anxiety and stress syndromes. J Abnorm Psychol. 1998; 107: 520-526. PubMed: https://www.ncbi.nlm.nih.gov/pubmed/9715586

15. French JRP, Caplan RD, Van Harrison R. The Mechanisms of Job Strain Stress \& Strain. Chichester, UK: Wiley. 1982.

16. Karasek RA. Job demands, job decision latitude, and mental strain: Implications for job redesign. Administrative Science Quarterly. 1979; 24: $285-308$

17. Kawakami N, Iwata N, Tanigawa T, Oga H, Araki S, et al. Prevalence of mood and anxiety disorders in a working population in Japan. J Occup Environ Med. 1996; 38: 899-905.

PubMed: https://www.ncbi.nlm.nih.gov/pubmed/8877839

18. Iliceto $P$, Pompili M, Spencer-Thomas S, Ferracuti S, Erbuto D, et al. Occupational stress and psychopathology in health professionals: an explorative study with the multiple indicators multiple causes (MIMIC) model approach. Stress. 2013; 16: 143-152.

PubMed: https://www.ncbi.nlm.nih.gov/pubmed/22632290 
19. Beehr TA, Franz TM. The current debate about the meaning of job stress. In J. M. Ivancevich \& D. C. Ganster (Eds.), Job Stress: From Theory to Suggestion. New York: The Haworth Press, 5-18. Desmarais S, Alksnis C. Gender Issues. In J. Barling, E. K. Kelloway, \& M. R. Frone (Eds.), Handbook of Work Stress. 1987.

20. Kam-Weng B, Kwok-Bun C, Yiu-Chung K, Lee-Gan G, Geok-Choo L. Work stress and Psychological Well-being among Nurses. In Kwok-bun, C. Work Stress and Coping among Professionals.

21. Stansfeld SA, Fuhrer R, Shipley M, Marmot M. Work characteristics predict psychiatric disorder: prospective results from the Whitehall II Study. Occup Environ Med. 1999; 56: 302-307.

PubMed: https://www.ncbi.nlm.nih.gov/pubmed/10472303
22. Fuhrer R, Stansfeld SA, Chemali J, Shipley MJ. Gender, social relations and mental health: prospective findings from an occupational cohort (Whitehall II study). Soc Sci Med. 1999; 48: 77-87.

PubMed: https://www.ncbi.nlm.nih.gov/pubmed/10048839

23. Andrea $H$, Bültmann $U$, van Amelsvoort LGPM, Kant $Y$. The incidence of anxiety and depression among employees-the role of psychosocial work characteristics. Depress Anxiety. 2009; 26: 1040-1048. PubMed: https://www.ncbi.nlm.nih.gov/pubmed/19242984

24. Kaori Y, Norio S, Norio Y, Kazuma D, Hanako F, et al. Relationship between occupational stress and depression among psychiatric nurses of Japan. Arch Environ Occup Health. 2016; 71: 10-15. PubMed: https://www.ncbi.nlm.nih.gov/pubmed/25148581 